\title{
INFLUÊNCIADO FOTOPERÍODO NO DESENVOLVIMENTO DE JUVENIS DE TAMBAQUI (COLOSSOMA MACROPOMUM)
}

\author{
INFLUENCE OF PHOTOPERIOD IN THE DEVELOPMENT OF JUVENILES OF TAMBAQUI \\ (COLOSSOMAMACROPOMUM)
}

\author{
Mendonça, P.P. ${ }^{1 *}$, R.A. Ferreira ${ }^{1}$, M.V. Vidal Junior ${ }^{1}$, D.R. Andrade ${ }^{1}$, M.V.B. Santos ${ }^{1}$, \\ A.V. Ferreira ${ }^{1}$ e F.P. Rezende ${ }^{1}$
}

'LZNA. CCTA. UENF. Av. Alberto Lamego 2000. Parque Califórnia. Campos dos Goytacazes. CEP 28013602. RJ-Brasil. *ppierro@pop.com.br

\section{PalaVRas chaVe adicionais}

Peixes brasileiros. Cachama. Nutrição de peixes. Bioclimatologia. Aqüicultura.

\section{RESUMO}

Cento e sessenta alevinos de tambaqui (Colossoma macropomum) (peso médio de $11,01 \pm 2,08 \mathrm{~g}$ e comprimento total de $7,8 \pm 0,18 \mathrm{~cm})$ condicionados em dezesseis aquários de 40 litros de água com temperatura de $29,1 \pm 0,413^{\circ} \mathrm{C}$, densidade de estocagem de 0,25 alevinos/l e aeração constante, com o objetivo de avaliar a quantidade de luz no desempenho produtivo dos peixes. Os tratamentos consistiram dos fotoperíodos: T1 $=6$ horas de luz:18 horas de escuro (06HL:18HE), T2=12HL:12HE, T3= 18HL:06HE e T4=24HL:0HE, com quatro repetições cada. Os alevinos foram alimentados duas vezes ao dia, com ração comercial extrusada ( $28 \%$ de proteína bruta). Diariamente era trocado 40 vezes o volume total da água. Ao final de 32 dias, foi avaliado comprimento total, comprimento padrão, altura, consumo de ração, ganho de peso e sobrevivência. Os resultados demonstraram que os maiores fotoperíodos influenciaram de forma positiva o desempenho produtivo dos alevinos de tambaqui.

\section{SUMMARY}

One hundred and sixty tambaqui fingerlings (Colossoma macropomum) (average weight of $11.01 \pm 2.08 \mathrm{~g}$ and total length of $7.8 \pm 0.18 \mathrm{~cm}$ ) conditional in sixteen aquariums of 40 liters of water with temperature of $29.1 \pm 0.413^{\circ} \mathrm{C}$, density of stockage of 0.25 fingerling/l and constant

Recibido: 13-2-07. Aceptado: 1-10-07.

\section{ADDITIONAL KEYWORDS}

Brazilian fish. Cachama. Nutrition of fish. Bioclimatology. Aquiculture.

aeration, with the objective to evaluate the amount of light in the productive performance of the fish. The treatments had consisted of the photoperiods: T1 $=6$ hours of light: 18 hours of dark (06HL:18HE), $\mathrm{T} 2=12 \mathrm{HL}: 12 \mathrm{HE}, \mathrm{T} 3=18 \mathrm{HL}: 06 \mathrm{HE}$ and $\mathrm{T} 4=24 \mathrm{HL}:$ $\mathrm{OHE}$, with four repetitions each. The fingerling had been fed two times a day, with extrused commercial ration ( $28 \%$ of rude protein). The total volume of water was changed 40 times daily. To the end of 32 days, it was evaluated total length, standard length, height, consumption of ration, weight gain and survival. The results show that greater photoperiods had influenced positively the productive performance of tambaqui fingerlings.

\section{INTRODUÇÃO}

O crescimento da população mundial tem resultado em uma maior demanda de alimento e com isso uma maior ação do homem sobre os recursos naturais. Sendo esse aumento no consumo de alimento proporcional ao crescimento do sedentarismo. Tem-se buscado associar maiores produções de alimentos com melhor qualidade do mesmo. Com isso o pescado tem cada vez mais encontrado lugar na base da alimentação.

O pescado proveniente da aqüicultura vem apresentando um crescimento contínuo 
nos últimos anos, enquanto a captura apresentou uma queda em 2003 (Crescencio, 2005).

Dados de produção nacional de água doce confirmam o crescimento da produção de peixes, bem como evidenciam o estabelecimento de algumas espécies em posição de destaque. Peixes como o tambaqui e o pacu possuem uma produção considerável dentre a produção total nacional: por três anos consecutivos apresentaram produção acima de 15000 t e 5000 t respectivamente (IBAMA, 2003, 2004).

Esse aumento na demanda mundial por peixe impulsiou a piscicultura nos últimos dez anos, fazendo com que ela se tornasse uma das atividades agopecuárias que mais crescem por ano. Isso levou a necessidade de se conhecer mais a fundo espécies com potencial para produção como a tilápia e a carpa, e espécies nativas, como tambaqui, pirarucu, pacu e outros.

A criação de espécies nacionais teve impulso com os esforços do Departamento Nacional de Obras Contra a Seca (DNOCS), fundado em 1993. O DNOCS desenvolveu esforços em reprodução, larvicultura produção de juvenis, ecologia em grandes açudes e criação de determinadas espécies, levando e disseminando espécies, principalmente amazônicas (Crescencio, 2005).

As espécies nativas de grande difusão pelo Brasil e pelo mundo são amazônicas, não só devido ao porte, crescimento ou sabor da carne, mais principalmente porque estas espécies evoluíram em ambiente hipóxico, ou anóxico em determinado período. Outro fator que contribui para difusão, em especial do tambaqui (Colossoma macropomum) e outras espécies de peixes redondos, pacu e pirapitinga, foi o desenvolvimento e difusão de um protocolo de reprodução de juvenis e a grande fecundidade destas espécies (Silva et al., 1981; Woynarovich, 1986).

O tambaqui, Colossoma macropomum (Cuvier, 1818), é uma espécie nativa das bacias dos rios Amazonas e Orinoco. Tem despertado interesse de pesquisadores e produtores, devido a sua adaptação ao cativeiro, rápido crescimento, fácil aceitação de alimento artificial e elevado valor de sua carne.

O tambaqui foi levado na década de 80 para o Panamá e para Taiwan; e, posteriormente, para Cuba, República Dominicana, Estados Unidos, Honduras, Jamaica, Filipinas, Guatemala, Hungria, Costa Rica, Porto Rico e China, onde são cultivados ou possuem populações livres na natureza (Liao etal., 2001).

O estado do Amazonas está situado entre os Trópicos de Capricórnio e Trópico de Câncer, região considerada tropical, onde ocorrem os maiores períodos de brilho solar e temperaturas elevadas. Sendo o tambaqui um peixe de hábito alimentar diurno e naturalmente pecilotérmico, está preparado para obter a maior quantidade de alimento e o melhor metabolismo durante períodos de maior brilho solar, ou maior luminosidade.

Pesquisas voltadas a influência da luz no desenvolvimento dessa espécie tornamse coerentes. E possuem resultados satisfatórios como os obtidos por, $\mathrm{Pu}-$ vannendran e Brown (2002) obtiveram que larvas de bacalhau do Atlântico (Gadus morhua), tiveram melhor crescimento e sobrevivência em alta intensidade luminosa e em fotoperíodos de 24HL:0HE*.

Fotoperíodos mais longos, 18 horas de luz e 6 horas de escuro (18HL:6HE) e 24HL:0HE, favoreceram a sobrevivência dos juvenis de linguado (Paralichthys orbignyanus), entretanto, o melhor crescimento foi obtido com 18HL:6HE (Louzada e Sampaio, 2004).

Em salmonídeos que recebem alimento à vontade, a exposição a um maior fotoperíodo aumenta a liberação de $\mathrm{GH}$, tirotropina, TSH e possivelmente esteróides, aumentando o crescimento (Baldisserotto, 2002). Villareal et al. (1998) citado por Salaro et al. (2006) relataram que o fotoperíodo atua de forma

\footnotetext{
*HL: horas de luz; HE: horas de escuro.
} 
positiva sobre o crescimento de larvas de salmão do atlântico (Salmo salar).

\section{MATERIALEMÉTODOS}

O experimento foi realizado no Setor de Aquicultura da Universidade Estadual do Norte Fluminense (UENF/RJ), situado no Colégio Agrícola Estadual Antônio Sarlo em Campos dos Goytacazes - RJ, durante o período de 4 de maio a 5 de junho de 2006 , com duração de 32 dias.

Foram utilizados 160 juvenis de tambaqui, Colossoma macropomum, com idade aproximada de 60 dias, distribuídos em 16 aquários com medidas aproximadas de $30 \mathrm{x}$ $60 \times 50$ (largura x comprimento x altura), utilizando um volume de 40 litros. O aquário e os 10 alevinos de tambaqui, juntos formavam as unidades experimentais.

As unidades experimentais foram distribuídas em um delineamento inteiramente casualizado, com quatro tratamentos e cada tratamento com quatro repetições, totalizando 16 unidades experimentais.

Os tratamentos diferenciaram em quantidade de horas de luz (HL) disponibilizada aos peixes, $\mathrm{T}=6 \mathrm{HL}, \mathrm{T} 2=12 \mathrm{HL}, \mathrm{T} 3=$ $18 \mathrm{HL}$ e T4=24HL. A quantificação da intensidade de luz utilizada no experimento foi feita através do aparelho Quantum Meter Photosynthetic Photon Flux, sendo a intensidade de luz medida em $\mu \mathrm{mol} \mathrm{m} \mathrm{m}^{2} \mathrm{~s}^{-1}$. O controle das horas de luz fornecidas durante o experimento foi feito por timers automáticos que apagavam e acendiam as luzes durante os períodos estipulados.

Cada tratamento estava isolado numa bancada de alvenaria e coberto por lona plástica preta, para evitar a incidência de luz proveniente de outras fontes luminosas durante o período de escuro de cada tratamento. Garantindo com isso que o fornecimento de luz só era feito durante os períodos estipulados para cada tratamento.

Foram mensurados os parâmetros de qualidade de água: oxigênio dissolvido, $\mathrm{pH}$, temperatura e condutividade elétrica, sempre após as refeições. Os níveis de oxigenação foram mantidos com auxílio de aeradores e mensurados através de um oxímetro, o pH foi medido através do peagâmetro, a temperatura com o uso de termômetro digital e a condutividade elétrica através do condutivímetro.

Os aquários experimentais encontravamse em sistema de recirculação fechada e contínua, contendo filtro dry-wet dotado de pré-caixa de decantação e caixa de retorno dotada de termostatos para a manutenção da temperatura da água.

A taxa de circulação da água foi de 40 vezes o volume total ao dia. O fluxo da água foi constante, visando manter o teor de oxigênio elevado e eliminar as fezes, evitando a formação de plâncton.

O manejo alimentar foi realizado utilizando uma ração comercial contendo $28 \%$ de $\mathrm{PB}$ e $3100 \mathrm{kcal}$ de ED $/ \mathrm{kg}$. A alimentação foi dividida em duas refeições diárias com intervalo de 5 horas entre a primeira e a segunda refeição. A ração foi fornecida às 8 e às 13 horas. Após 15 minutos, as sobras eram retiradas dos aquários e onde não havia sobra, foi repetida a alimentação, até que o mesmo apresentasse sobras.

Foi utilizada uma densidade inicial equivalente a 3,05 g de peixe/l por aquário. Os alevinos passaram por um processo de adaptação à rotina experimental de 12 dias. Ao iniciar o experimento e a cada 16 dias, foram feitas biometrias dos alevinos, onde foram mensurados: comprimento corporal total, comprimento corporal padrão, altura corporal, peso corporal e consumo de ração.

Comprimento corporal total, CT $(\mathrm{cm})$ : distância entre a boca e a extremidade distal da nadadeira caudal.

Comprimento corporal padrão, $\mathrm{CP}(\mathrm{cm})$ : distância entre a boca e a extremidade proximal da nadadeira caudal.

Altura corporal, H (cm): distância entre as extremidades dorsal e ventral do corpo, obtida a partir do traçado perpendicular da inserção do primeiro raio da nadadeira dorsal. 
Peso corporal, $\mathrm{P}(\mathrm{g})$ : biomassa do peixe vivo.

Consumo de ração, $\mathrm{CR}(\mathrm{g})$ : relação feita pela quantidade de ração oferecida $(\mathrm{g}) \mathrm{me}$ nos a quantidade de ração não consumida (g).

Essas biometrias junto com o manejo alimentar permitiram o cálculo de alguns parâmetros como: ganho de peso corporal, conversão alimentar, consumo de ração, taxa de ganho de peso diária, taxa de crescimento diário, ganho de crescimento, taxa especifica de crescimento, taxa de eficiência protéica e eficiência de retenção de proteína bruta, no final do experimento.

Ganho de peso corporal, GP (g): é a diferença entre o peso final e o peso inicial.

Conversão alimentar, $\mathrm{CA}(\mathrm{g})$ : é a relação entre CR (g) e ganho de peso (g).

Consumo de ração, CR ( $\mathrm{g})$ : é a diferença entre o peso de ração fornecido (g) e o peso da sobra de ração $(\mathrm{g})$.

Taxas, Tx: é a divisão da variável de interesse pelo número de dias do período avaliado.

Taxa de crescimento especifico, TCE (\%): é o (log do peso final - log do peso inicial) $\mathrm{x} 100$ / período.

Taxa de eficiência protéica, TEP ou PER (\%): é a divisão do ganho de peso pela quantidade de proteína ingerida.

Eficiência de retenção de proteína bruta ERPB ou ANPU: é o peso em proteína bruta na matéria natural dividido pelo consumo em proteína.

Ao término do experimento, foram feitas coletas de sangue para mensuração de glicose sanguínea com o objetivo de verificar indicadores de estresse nos peixes.

Foi obtida amostra do sangue de três peixes de cada unidade experimental. Para esta coleta foram utilizadas seringas de $3 \mathrm{ml}$ com agulhas 25/7, o conjunto (seringas e agulhas) foi lavado com fluoreto de potássio, com o objetivo de evitar a coagulação e a glicólise sanguínea.

Para a coleta de sangue, os peixes foram anestesiados com uma solução contendo
$65 \mathrm{ppm}$ de eugenol. A coleta de sangue foi feita através de pulsão da veia caudal, retirando um volume mínimo de $0,4 \mathrm{ml}$ de sangue por peixe. O sangue foi transferido das seringas para tubos de ensaio, que foram centrifugados a $3500 \mathrm{rpm}$ por cinco minutos, retirou-se o plasma que foi centrifugado novamente a mesma velocidade e tempo, para retirada total de resíduos da parte sólida.

Após separação do plasma, o mesmo foi acondicionado em micro tubo e guardado em bandeja de isopor enrolado com filme pvc, posteriormente analisados no Setor de Patologia Clínica \LSA \CCTA\UENF, através de espectrofotometria.

A análise estática do experimento foi feita através do programa estatístico SAEG versão 9.1 (2007), da Universidade Federal de Viçosa. Foram feitas análise de variância, regressões lineares simples e múltiplas e correlações de Pearson, com os dados obtidos através das mensurações feitas durante o período experimental.

\section{RESULTADOSEDISCUSSÃO}

Os valores dos parâmetros relacionados à qualidade da água, oxigênio dissolvido $\left(\mathrm{O}_{2} \mathrm{D}\right)$, temperatura $\left(\mathrm{T}^{\circ} \mathrm{C}\right)$, potencial hidrogeniốnico $(\mathrm{pH})$ e condutividade elétrica $(\mathrm{CE})$, mensurados durante o período experimental, estão na tabela $\mathbf{I}$.

Tabela I. Valores médios dos parâmetros físico-químicos da água nos tratamentos do Experimento I. (Average values of physical and chemical parameters of water treatment (experiment I)).

\begin{tabular}{|c|c|c|c|c|}
\hline \multirow[b]{2}{*}{ Parâmetros } & \multicolumn{4}{|c|}{ Tratamento } \\
\hline & 6 & 12 & 18 & 24 \\
\hline $\mathrm{O}_{2}$ dissolvido (mg/l) & 5,9 & 5,8 & 5,6 & 5,7 \\
\hline $\mathrm{pH}$ & 6,17 & 6,08 & 5,72 & 5,76 \\
\hline Condutividade $(\mu S)$ & 366 & 396 & 543 & 561 \\
\hline Temperatura $\left({ }^{\circ} \mathrm{C}\right) \mathrm{M}$ & 29,5 & 29,8 & 29,1 & 29,4 \\
\hline $\mathrm{T}$ & 29 & 28,9 & 28,6 & 28,7 \\
\hline
\end{tabular}


O teor médio de oxigênio dissolvido, durante o período experimental, foi de 5,75 mg/l. Segundo Araujo-Lima e Gomes (2005), o tambaqui tem seu crescimento normal em níveis de oxigênio acima de $3 \mathrm{mg} / 1$, portanto os valores de obtidos no experimento ora descrito, atendem perfeitamente a exigência do tambaqui. Da mesma forma, a média do potencial hidrogeniônico manteve-se dentro dos padrões recomendados por Aride $e t$ al. (2004), entre 4,0 e 6,5. A temperatura dos aquários experimentais mostrou-se adequada para espécies de clima tropical, apresentando médias $29,45^{\circ} \mathrm{C}$ pela manhã e $28,8^{\circ} \mathrm{C}$ pela tarde.

As intensidades de luz utilizadas no experimento não diferiram entre os tratamentos, $\mathrm{T} 1=0,1067 ; \mathrm{T} 2=0,1050 ; \mathrm{T} 3=0,1050$; $\mathrm{T} 4=0,0967 \mu \mathrm{mol} \mathrm{m}^{-1} \mathrm{~s}^{-1}$, porém dentro dos próprios tratamentos ocorreu uma diferença entre a quantidade de $\mu \mathrm{mol} \mathrm{m}^{-1} \mathrm{~s}^{-1}$ oferecidos às repetições, 0,$0713 ; 0,1416 ; 0,0925 \mu \mathrm{mol} \mathrm{m}$ ${ }^{1} \mathrm{~s}^{-1}$, sendo os valores, lateral esquerda, meio e lateral direita respectivamente. Isto pode explicar o elevado coeficiente de variação encontrado entre as repetições dentro de um próprio tratamento.

Com relação aos resultados obtidos com a biometria aferida no presente trabalho (tabela II) foram observadas maiores respostas quanto as variáveis de comprimento, comprimento total (CT) e comprimento padrão $(\mathrm{CP})$, e a variável peso $(\mathrm{P})$, nos tratamentos com maior quantidade de luz, T4(24HL:0HE) e T3 (18HL:6HE), respectivamente. Demonstrando assim um melhor desenvolvimento dos juvenis de tambaqui.

Diversos autores têm relatado que o aumento na duração do fotoperíodo luminoso tem efeito positivo no desenvolvimento dos peixes. Fotoperíodos longos (18HL:6HE e 24HL:0HE) proporcionaram melhores resultados no desenvolvimento de larvas de Latris lineatus do que o fotoperíodo mais curto (12HL:12HE) (Trotter etal., 2003).

Resultados semelhantes têm sido relatados para diferentes espécies e fases de desenvolvimento, como o melhor desenvolvimento para larvas de Paralichthys lethostigma (Moustakas et al., 2004), larvas de bacalhau do Atlântico (Gadus

Tabela II. Valor médio de comprimento total $(C T)$, altura $(H)$, consumo de ração $(C R)$, ganho de peso (GP), conversão alimentar (CA), peso, glicose, taxa de eficiencia proteica (TEP), taxa de crescimento especifico (TCE), obtidos para juvenis de tambaqui aos 32 dias nos diferentes fotoperiodos emerais. (Average values for total lenght $(\mathrm{CT})$, heigh $(\mathrm{H})$, feed intake (CR) weight gain (GP), feed conversion (CA), weight, glicose, protein efficiency rate (TEP), and specific growth rate (TCE) for juvenile tambaqui at 32 days and different photoperiods).

\begin{tabular}{|c|c|c|c|c|c|c|c|c|}
\hline \multirow[t]{2}{*}{ Vareaveis } & \multicolumn{8}{|c|}{ Tratamentos (horas de luz) } \\
\hline & 6 & CV & 12 & $\mathrm{CV}$ & 18 & CV & 24 & CV \\
\hline $\mathrm{CT}(\mathrm{cm})$ & 11,13 & 4,49 & 11,10 & 4,41 & 11,23 & 2,94 & 11,78 & 4,07 \\
\hline $\mathrm{H}(\mathrm{cm})$ & 4,78 & 7,13 & 4,70 & 3,47 & 4,73 & 3,61 & 5,15 & 4,04 \\
\hline CR $(g)$ & 22,05 & 12,18 & 24,81 & 11,34 & 22,62 & 12,69 & 29,61 & 13,76 \\
\hline GP $(g)$ & 18,02 & 18,48 & 19,80 & 16,73 & 18,77 & 15,05 & 26,04 & 22,34 \\
\hline CA $(g)$ & 1,24 & 8,47 & 1,26 & 5,99 & 1,21 & 5,73 & 1,15 & 8,57 \\
\hline Peso (g) & 30,31 & 10,81 & 32,05 & 10,79 & 30,88 & 6,52 & 38,08 & 13,76 \\
\hline Glicose (mg/dl) & 98,75 & 12,90 & 80,15 & 16,24 & 72,30 & 7,03 & 64,78 & 8,51 \\
\hline TEP $(\%)$ & 2,31 & 8,03 & 2,35 & 6,03 & 2,38 & 5,82 & 2,43 & 9,14 \\
\hline TCE $(\%)$ & 1,13 & 10,11 & 1,26 & 24,77 & 1,24 & 18,80 & 1,45 & 12,83 \\
\hline
\end{tabular}

$C V=$ Coeficiente de variação. 
morhua) (Puvannendran e Brown, 2002) e juvenis de Melanogrammus aeglefins (Trippel e Neil, 2003), tiveram melhores resultados de crescimento e sobrevivência quando expostos a fotoperíodos longos com altas intensidades luminosas.

Ao contrário dos resultados apresentados existem autores que não observaram diferenças significativas ou respostas positivas com o aumento do fotoperíodo, para o desenvolvimento dos estágios iniciais da piscicultura.

Reynalte-Tataje et al. (2002), trabalhando com larvas de piracanjuba Brycon orbignyanus, não constatou diferença significativa para comprimento e para peso $(\mathrm{p}>0,05)$, durante o período experimental de 10 dias, quando esta foram submetidas a fotoperíodos equivalentes a $0 \mathrm{HL}: 24 \mathrm{HE}$, 10HL:14HE, 14HL:10HEe24HL:0HE.

Observou também maior heterogeneidade com a diminuição do fotoperíodo, sendo observados valores máximos e mínimos de peso no tratamento 0HL:24HE de 12 a $94 \mathrm{mg}$ ( 11 e $22 \mathrm{~mm}$, respectivamente).

Com relação as variáveis ganho de peso (GP), consumo de ração (CR), conversão alimentar (CA) e sobrevivência, os maiores resultados foram obtidos com os maiores fotoperíodos. Sendo que para sobrevivência e canibalismo não houve diferença entre os resultados obtidos nos tratamentos.

Salaro et al. (2006), trabalhando com alevinos de trairão (Hoplias lacerdae), também não observou diferença significativa para o ganho de peso, conversão alimentar, taxas de sobrevivência e canibalismo.

Luz et al. (2000), também não encontraram diferença significativa quando avaliaram o desenvolvimento de larvas de surubim cachara (Pseudoplatystoma fasciatum) submetido a 24HL:0HE e 0HL:24HE.

Além das variáveis já citadas nos parágrafos anteriores, foram ainda medidas a taxa de crescimento especifico (TCE), a taxa de eficiência protéica (TEP ou PER), a glicemia sanguínea, as taxas de ganhos diários de $\mathrm{CT}, \mathrm{CP}, \mathrm{H}$, nos intervalos de 16 dias e nos períodos acumulados no experimento (tabela III).

Com relação a TCE dos valores médios obtidos nos tratamentos, T1, T2, T3, T4 foram respectivamente 1,$13 ; 1,26 ; 1,24$ e 1,45 $\% /$ dia, demonstrando uma maior diferença do valor obtido com o tratamento de 24HL;0HE aos demais tratamentos. Sendo estes valores superiores aos valores encontrados por Ituassú et al. (2004), trabalhando com juvenis de tambaqui pesando em média 75,68 g, encontraram médias de TCE que variarão de 0,97 ate $0,83 \%$ ao dia.

Já Fernandes et al. (2000), estimou valo-

Tabla III. Valores médios de taxa de eficiência protéica (TEP), taxa de crescimento especifico (TCE), taxas de ganho de comprimento total (TxGCTD), comprimento padrão (TxGCPD) e altura (TxGHD) diárias de juvenis de tambaqui em diferentes fotoperíodos. (Average values of protein efficiency rate (PTE), specific growth rate (ECA), rates of total length gain (TxGCTD), standard length (TxGCPD) and height (TxGHD) of juvenile tambaqui in different photoperiods).

\begin{tabular}{lcccc}
\hline & & \multicolumn{2}{c}{ Tratamento } & \\
& 6 & 12 & 18 & 24 \\
\hline TEP & $2,31 \pm 0,57$ & $2,35 \pm 0,64$ & $2,38 \pm 0,66$ & $2,43 \pm 0,82$ \\
TCE & $1,13 \pm 0,06$ & $1,26 \pm 0,11$ & $1,24 \pm 0,06$ & $1,45 \pm 0,23$ \\
TxGCTD & $0,0985 \pm 0,0046$ & $0,1101 \pm 0,0141$ & $0,1140 \pm 0,0092$ & $0,1299 \pm 0,0264$ \\
TxGCPD & $0,0965 \pm 0,0096$ & $0,1032 \pm 0,0137$ & $0,1060 \pm 0,0141$ & $0,1195 \pm 0,0238$ \\
TxGHD & $0,0722 \pm 0,0618$ & $0,0962 \pm 0,1088$ & $0,0984 \pm 0,1105$ & $0,1071 \pm 0,1161$ \\
ERPB & 0,2743 & 0,2817 & 0,2610 & 0,2438 \\
& & & & \\
\hline
\end{tabular}

Archivos de zootecnia vol. 58, núm. 223, p. 328. 
res maiores de TCE entre 1,64 e 1,80\%/dia para alevinos de pacu, assim como Ituassú et al. (2005), trabalhando com juvenis de pirarucu obtiveram valores entre 1,4 a 2,4\%/ dia de TCE, com variação nos níveis de proteína bruta.

Sendo que Muñoz-Ramirez (2002), obtiveram valores ainda maiores, entre 2,27 e 1,76\% ao dia de TCE para etapa inicial do crescimento de pacu submetidos a diferentes suplementações de lisina e metionina em rações com baixo valor protéico.

A ração utilizada no experimento apresenta um valor protéico equivalente a $28 \%$ de proteína bruta. Este valor esta próximo ao valor ideal de proteína bruta para juvenis de tambaqui preconizados por Vidal Júnior (1995), que trabalhando com juvenis de tambaqui, de 30 a $250 \mathrm{~g}$, a uma temperatura de $25,8^{\circ} \mathrm{C}$, obtiveram máximo desempenho quando alimentados com ração contendo 25,1\% de PB, e por Fernandes et al. (2000), que observaram não haver diferença significativa entre rações isocalóricas, porém com 30 e $26 \%$ de proteína bruta, para o crescimento de juvenis de pacu.

Os peixes submetidos aos tratamentos com maiores fotoperíodos apresentaram as maiores taxas de eficiência protéica (TEP), sendo os valores 2,$31 ; 2,35 ; 2,38$ e 2,43, para os tratamentos $\mathrm{T} 1, \mathrm{~T} 2, \mathrm{~T} 3$ e $\mathrm{T} 4$ respectivamente.

Estes valores estão próximos ao valores encontrados em Muñoz-Ramirez e Carneiro (2002), que obtiveram valores de TEP entre 2,34 e 2,73 trabalhando com juvenis de pacu.

Porém esse valores são inferiores ao encontrados por Fernandes et al. (2000), que obteve valores para alevinos de pacu, em torno de 3,23 a 2,92, quando alimentados com dietas contendo diferentes níveis e fontes de proteína.

Para quantificação do estresse durante o período experimental foi dosada a glicemia sanguínea, sendo obtidos resultados na primeira coleta, com trinta e dois dias, indicando um leve estresse para os peixes nos menores fotoperíodos e na segunda coleta, com sessenta e quatro dias, todos os tratamentos apresentaram valores de glicemia indicado estresse. Os valores da glicemia estão na tabela II.

Quando o peixe encontra-se numa situação desfavorável aumenta o nível de glicose sanguínea, como demonstrado por Martins et al. (2002), quando submetera o híbrido tambacu a estímulos consecutivos de estresse, partindo de um valor inicial de $71,00 \mathrm{mg} / \mathrm{dl}$ no tempo zero e chegando a alcançar valores de 148,35 e 119,57 nos tempos T4 e T5 respectivamente.

Brandão et al. (2004), quantificaram o nível de glicose sanguínea de tambaquis, durante um experimento de densidade, no qual não acharam diferença significativa para as densidades escolhidas com relação ao estresse. Chagas et al. (2002), testando densidades de estocagem de tambaqui, apresentaram os seguintes valores de glicose sanguínea, 61,80; 67,30 e 63,67 mg/ $\mathrm{dl}$, para as respectivas densidades de estocagem, 25; 50 e 75 peixes por $\mathrm{m}^{3}$, não demonstrando a presença de fatores estressantes durante o experimento.

Gomes et al. (2001), quantificaram valores de glicose sanguínea para o juvenis de tambaqui em situação de repouso, chegando a valores dentro do intervalo de 50 a $70 \mathrm{mg}$ / dl.

Os maiores valores mensurados das variáveis citadas neste experimento estão correlacionados com diversos fatores, porém o fato que peixes como o tambaqui, apresentam ciclo alimentar diurno e tem na visão a principal ferramenta para localização do alimento, fotoperíodos maiores possibilitam e estimulam melhor utilização do alimento para o desenvolvimento. Também deve-se considerar a fase de desenvolvimento dos tambaquis usados no experimento, como os juvenis, onde naturalmente estão na base da cadeia trófica de ecossistemas aquáticos, na qual a luz permite melhor visualização do ambiente, deixando uma maior sensação de segurança, com isso menor estresse e maior crescimento. 
Tabla IV. Valores de correlação obtidos através da correlação de Pearson, para as variáveis, $T E P, C R, E R P B, C A, C T, C P, H, G C P, G H, P, T C E$ e. GP. (Pearson's correlation values for the variables, TEP, CR, ERPB, CA, CT, CP, H, GCP, RI, P, TEC, e GP).

\begin{tabular}{lcccccccccc}
\hline & TEP & CR & CA & CT & CP & H & GCP & GH & P & GP \\
\hline CR & 0,6799 & - & - & - & - & - & - & - & - & - \\
CA & $-0,9938$ & $-0,6664$ & - & - & - & - & - & - & - & - \\
CT & - & 0,5708 & - & - & - & - & - & - & - & - \\
CP & - & 0,5930 & - & 0,9962 & - & - & - & - & - & - \\
H & 0,7617 & 0,8892 & $-0,7705$ & - & - & - & - & - & - & - \\
GCP & - & - & - & 0,9962 & - & - & - & - & - & - \\
GH & 0,7617 & 0,8892 & $-0,7705$ & - & - & - & 0,8977 & - & 0,9036 & - \\
P & 0,8051 & 0,9660 & $-0,7848$ & - & 0,5898 & 0,9036 & - & - & - & 0,9902 \\
TCE & 0,8618 & 0,9332 & $-0,8503$ & 0,8737 & - & - & - & 0,8737 & - & 0,9763 \\
GP & 0,8392 & - & $-0,8188$ & 0,8977 & - & - & - & - & - & - \\
\hline
\end{tabular}

Foi feita correlação de Pearson para as variáveis obtidas durante o período experimental, sendo as correlações acima de $60 \%$ apresentadas na tabela IV.

Pode-se observar que a taxa de eficiência protéica (TEP) e a eficiência de retenção de proteína bruta (ERPB) demonstraram uma correlação negativa com a variável conversão alimentar (CA), o que demonstra que quanto menor for o valor das variáveis TEP e ERPB, maior será o valor da conversão alimentar, demonstrando com isso, uma pior

\section{BIBLIOGRAFIA}

Araujo-Lima, C.A.R.M. e L.C. Gomes. 2005. Espécies nativas para piscicultura no Brasil. Cap. Tambaqui, p.179. Ed. da UFSM. Santa Maria. $468 p$.

Aride, P.H.R., R.E Roubach and A.L. Val. 2004. Water $\mathrm{pH}$ in central Amazon and its importance for tambaqui (Colossoma macropomum) culture. World Aquacult., 35: 24-27.

Baldisserotto, B. 2002. Fisiologia de peixes aplicada à piscicultura. Ed. UFSM. Santa Maria. 212p

Brandão, F.R., L.C. Gomes, E.C. Chagas e L.D. Araujo. 2004. Densidade de estocagem de juvenis de tambaqui durante a recria em tanquerede. Pesqui. Agropecu. Bras., 39: 357-362.

Chagas, E.C., J.N.P. Lourença e A.L. Val. 2002. Desempenho e estado de saúde de tambaquis cultivados em tanques-rede sob diferentes utilização do alimento para o desenvolvimento dos alevinos de tambaqui.

Os maiores fotoperíodos demonstraram influência positiva sobre o nível de glicemia sanguínea, o que proporcionou um ambiente menos estressante aos juvenis de tambaqui.

A maior disponibilidade de luz possibilitou a melhor utilização da alimentação fornecida durante o período experimental, para o melhor desenvolvimento e crescimento dos juvenis de tambaqui, Colossoma macropomum.

densidades de estocagem. Simpósio Brasileiro de Aqüicultura, 12, 2002, Goiânia. Anais. Aquabio. Jaboticabal. p. 83-93.

Crescencio, R. 2005. Ictiofauna brasileira e seu potencial para criação. Em: Espécies nativas para piscicultura no Brasil. Baldisserotto, B. e Gones, L.C. Cap 1. p. 29. Ed. Da UFSM. Santa Maria. 468 p.

Fernandes, J.B.K., D.J. Carneiro e N.K. Sakomura. 2000. Fontes e níveis de proteína bruta em dietas para alevinos de pacu (Piaractus mesopotamicus). Rev. Bras. Zootecn., 29: 646-653. Gomes, L.C., A.R. Chipiri-Gomes, N.P. Lopes, R. Roubach and C.A.R.M. Araújo-Lima. 2001. Efficacy of benzocaine as anesthesic for tambaui juveniles (Colossoma macropomum). J. World Aquacult. Soc., 31: 426-431. 


\section{INFLUENCIA DO FOTOPERIODO NO DESENVOLVIMENTO DE JUVENIS DE TAMBAQUI}

IBAMA. 2003. Instituto Brasileiro do Meio Ambiente e dos Recursos Naturais Renováveis. Estatística da Pesca 2001. Brasil Grandes regiões e unidades da federação. Brasília. 97 p.

IBAMA. 2004. Instituto Brasileiro do Meio Ambiente e dos Recursos Naturais Renováveis. Estatística da Pesca 2003. Brasil Grandes regiões e unidades da federação. Brasília. $98 \mathrm{p}$.

Ituassú, D.R., G.R.S. Santos, R. Roubach e M. Pereira-filho. 2004. Níveis de proteína bruta para juvenis de pirarucu. Pesqui. Agropecu. Bras., 40: 255-259.

Ituassú, D.R., M. Pereira-filho, R. Roubach, R. Crescencio, B.A.S. Caveiro e A.L. Gandra 2005. Desenvolvimento de tambaqui submetido a periodos de privação alimentar. Pesqui. Agropecu. Bras., 40: 255-259.

Liao, I.C., H.M. Su and E.Y. Chang. 2001. Techniques in finfish larviculture in Taiwan. Aquaculture, 200: 1-31.

Louzada, L.R. e L.A. Sampaio. 2004. Efeito do fotoperíodo sobre o crescimento e a sobrevivência de juvenis do linguado (Paralichthys orbignyanus). In: Aqüimerco, 1., 2004. Vitória. Anais. Aquabio. Vitória.

Luz, R.K., A.L.Salaro, R.N. Sirol, M.R.Toledo e R.R.Lima. 2000. Influência do fotoperíodo no desenvolvimento inicial de surubim cachara (Pseudoplatystoma fasciatum). Em: Reunião Anual da Sociedade Brasileira de Zootecnia, 37. Viçosa. Resumos. SBZ. Viçosa. 2000.

Martins, M.L., F.R. Moraes, R.Y. Fujimoto, D.T. Nomura e J. Fenerick Jr. 2002. Resposta do hibrido tambacu (Piaractus mesopotamicus Homberg, 1887 macho x Colossoma macropomum Cuvier, 1818 femea) a estímulos simples e conscutivos de captura. Bol. Instituto Pesca, 28: 195-204.

Moustakas, C.T., W.O. Watanabe and K.A. Copeland. 2003. Combined effects of photoperiod and salinity on growth, survival, and osmoregulatory ability of larval southern flounder (Paralichthys lethostigma). The University of North Carolina at. Wilmington, Center for Marine Science. Wilmington.

Muñoz-Ramirez, A.P. e D.J. Carneiro. 2002.
Suplementação de lisina e metionina em dietas com baixos níveis protéicos para o crescimento inicial do pacu, Piaractus mesopotamicus (Holmberg). Acta Scientiarum, 24: 909-916.

Puvannendran, V. and J.A. Brown. 2002. Foraging, growth and survival of Atlantic cod larvae reared in different light intensities and photoperiods. Aquaculture, 214: 131-151.

Reynalte-Tataje, D., R.K. Luz, S. Meurer, E. Zaniboni-Filho e A.P.O. Nuner. 2002. Influencia do fotoperíodo no crescimento e sobrevivência de pós-larvas de piracanjuba Brycon orbignyanusi (Valenciennes, 1849) (Osteichthyes, Characidae). Acta Scientiarum, 24: 439-443.

Salaro, A.L, R.K. Luz, J.A.S. Zuanon, R.N. Sirol, R. Sakabe, W.A.G. Araújo e E.S. Ferri. 2006. Desenvolvimento de alevinos de trairão (Hoplias lacerdae) na ausência de luz. Acta. Sci. Biol. Sci., 28: 47-50.

Silva, A.B., A. Carneiro-Sobrinho e F.R. Melo. 1981. Desova induzida de tambqui, Colossoma macropomum, Cuvier, 1818, com uso de hipófise de curimatá comum, Prochilodus cearensis Steindachner. Em: DNOCS. $2^{\text {a }}$ Coletania de trabalhos técnicos. CE. Ed. Ministerio do Interior. Fortaleza. p. 519-532.

Trippel, E.A. e S.R.E. Neil. 2002. Effects of photoperiod and intensity on growth and activity of juvenile haddock (Melanogrammus aeglefinus) light. Aquaculture, 217: 633-645.

Trotter, A.J., S.C. Battagleneand P.M. Pankhurst 2003. Effects of photoeriods and light intensity on initial swin bladder inflation, growth and post inflation viability in cultured stripped trumpeter (Latris lineatus) larvae. Aquaculture, 224: 141158.

SAEG. 2007. Sistema de Análises Estatísticas e Genéticas. Versão 9.1. Universidade Federal de Viçosa. Viçosa, MG. 142 p.

Vidal Junior, V.V. 1995. Níveis de proteína para tambaqui (Colossama macropomum Curvier, 1818) dos 30 aos $250 \mathrm{~g}$ de peso vivo. Tese M.S. UFV. Viçosa. $49 \mathrm{p}$.

Woynarovich, E. 1986. Tambaqui e pirapitinga: propagação artificial e criação de alevinos. $3^{\text {a }}$ ed. CODEVASF. Brasília. 68 p. 